\title{
Resolution of obstructive sleep apnoea with growth in the Robin sequence
}

\author{
J.L. Kiely, P.C. Deegan, W.T. McNicholas
}

\begin{abstract}
Resolution of obstructive sleep apnoea with growth in the Robin sequence. J.L. Kiely, P.C. Deegan, W.T. McNicholas. CERS Journals Ltd 1998.

ABSTRACT: A 12 year old female with the Robin sequence presented with a one year history of snoring, witnessed apnoeas and daytime sleepiness. Surgery in early childhood had consisted of cleft palate repair, tonsillectomy and adenoidectomy and, later, revision palatoplasty. Overnight polysomnography (PSG) demonstrated severe obstructive sleep apnoea syndrome with an apnoea/hypopnoea index (AHI) of 49 events $\cdot h^{-1}$ and repetitive oxygen desaturations below $50 \%$. Nasal continuous positive airway pressure (nCPAP) effectively controlled her sleep abnormalities. After 3 yrs of nCPAP therapy, she requested discontinuation and was fully reassessed. PSG without nCPAP revealed an AHI $<5$ events $h^{-1}$ with no desaturations below $90 \%$ and normal sleep quality. A repeat lateral cephalometrogram showed increased mandibular length and posterior airway space and reduced soft palate length. The patient remains asymptomatic 9 months following nCPAP discontinuation.

This case indicates that nasal continuous positive airway pressure is an effective nonsurgical therapy in children with obstructive sleep apnoea syndrome and the Robin sequence. It is likely that mandibular growth, increase in mandibular length and enlargement of the posterior airway space was responsible for the resolution of obstructive sleep apnoea syndrome in this case. Eur Respir J 1998; 12: 499-501.
\end{abstract}

Respiratory Sleep Laboratory, Dept of Respiratory Medicine, St Vincent's Hospital, Dublin, Ireland.

Correspondence: W.T. McNicholas

Dept of Respiratory Medicine

St Vincent's Hospital

Elm Park

Dublin 4

Ireland

Fax: 35312697949

Keywords: Growth

obstructive sleep apnoea

Robin sequence

Received: September 41997

Accepted after revision March 101998

J.L. Kiely is funded by an Irish Health Research Board Post Doctoral Fellowship.
The Robin sequence is a congenital disorder characterized by micrognathia and cleft palate [1] and has been associated with a predisposition to obstructive sleep apnoea (OSA) [2-4]. The associated posterior displacement of the tongue (glossoptosis) results in a narrowed upper airway (UA), which favours UA collapse during inspiration [5, 6]. We report a case of severe OSA in a teenage female with the Robin sequence, which was successfully treated with nasal continuous positive airway pressure (nCPAP) and in whom the OSA resolved spontaneously over a three-year period associated with changes in UA bony and soft tissue dimensions.

\section{Case report}

The patient details and initial response to nCPAP have previously been reported elsewhere [7], and are summarized as follows. A $12 \mathrm{yr}$ old female with Robin sequence presented with a history of habitual snoring since infancy and witnessed apnoeas during sleep over the previous 12 months. A cleft palate repair had been performed at the age of 11 months, a tonsillectomy/adenoidectomy at the age of $5 \mathrm{yrs}$, and palatoplasty 2 yrs later to correct a speech disturbance. The patient complained of chronic fatigue and sleepiness, frequent nocturia and occasional nocturnal enuresis. Her weight was $29 \mathrm{~kg}$ ( $3 \mathrm{rd}$ centile) and height 150 $\mathrm{cm}$ (50th centile). Apart from prominent micrognathia and a resting tachycardia, physical examination was normal. A 12-lead electrocardiogram (ECG) showed sinus tachycar- dia (110-115 beats.min $\left.{ }^{-1}\right)$ and p-pulmonale, suggesting right-heart strain.

Full overnight sleep studies using standard polysomnographic techniques [8] demonstrated severe OSA with 49 obstructive apnoeas (no airflow despite inspiratory effort) or hypopnoeas (tidal volume $<50 \%$ baseline, with associated $\mathrm{O}_{2}$ desaturation $\breve{\mathrm{S}} 4 \%$ ) per hour of sleep and associated oxygen desaturations to levels below $50 \%$ (fig. 1). She had poor quality sleep with no slow wave sleep (SWS) or rapid-eye movement (REM) sleep. The OSA was effectively controlled with nCPAP (REMstar ${ }^{\mathrm{TM}}$; Respironics, Murrayville, PA, USA) at a pressure level of $14 \mathrm{cmH}_{2} \mathrm{O}$ and this therapy was associated with an immediate improvement in energy and daytime sleepiness. Follow-up sleep studies and assessment on nCPAP after 6 and 18 months of continuous therapy at home showed abolition of apnoeas and hypopnoeas, normal oxygen saturation $\left(\mathrm{Sa}_{\mathrm{a}} \mathrm{O}_{2}\right)$, and normal amounts of SWS and REM sleep with no further daytime sleepiness, nocturia or nocturnal enuresis. Her ECG had reverted to normal and nCPAP pressure was reduced to $10 \mathrm{cmH}_{2} \mathrm{O}$, without the reappearance of apnoea or hypopnoeas.

After 3.5 yrs of continuous nCPAP therapy, aged $16 \mathrm{yrs}$, she had grown to $162 \mathrm{~cm}$ (50th centile) and weighed 50.5 $\mathrm{kg}$ (25th centile). She wished to try sleeping without nCPAP and, therefore, full polysomnography (PSG) was repeated after 1 week without the device. This study showed that her OSA had resolved and oxygen saturation remained $>90 \%$ throughout sleep. Nasal CPAP was discontinued and a further follow-up PSG after 6 months confirmed 


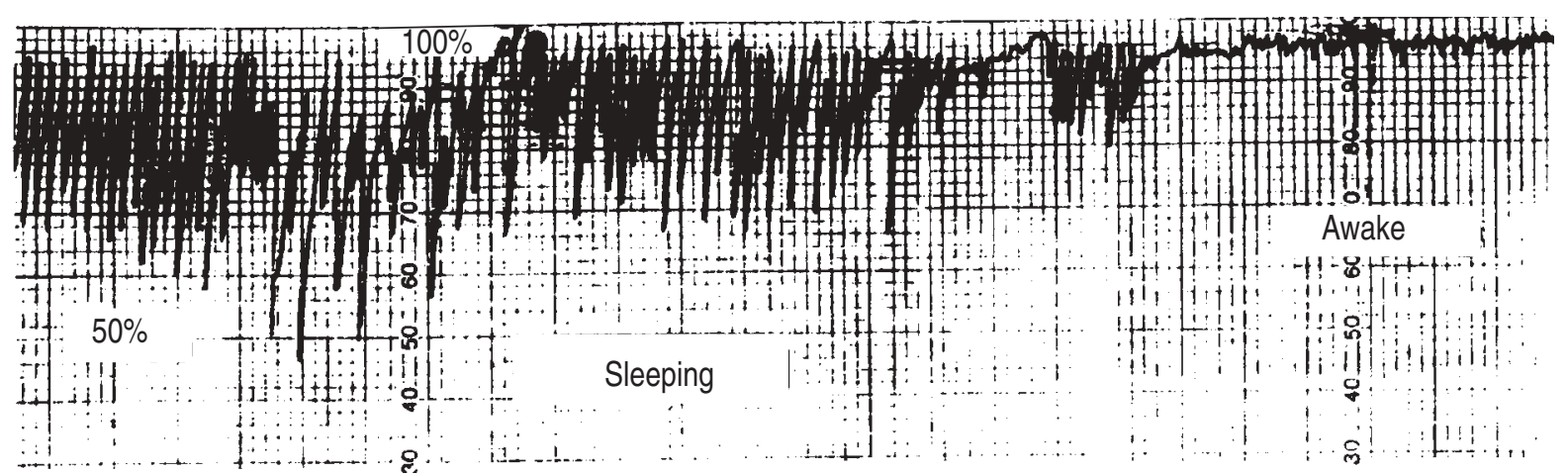

Fig. 1. - Oximetry tracing (reading from right to left). Awake (normal oxygen saturation) to sleep (repetitive severe oxygen desaturations) in patient, aged 12 yrs.

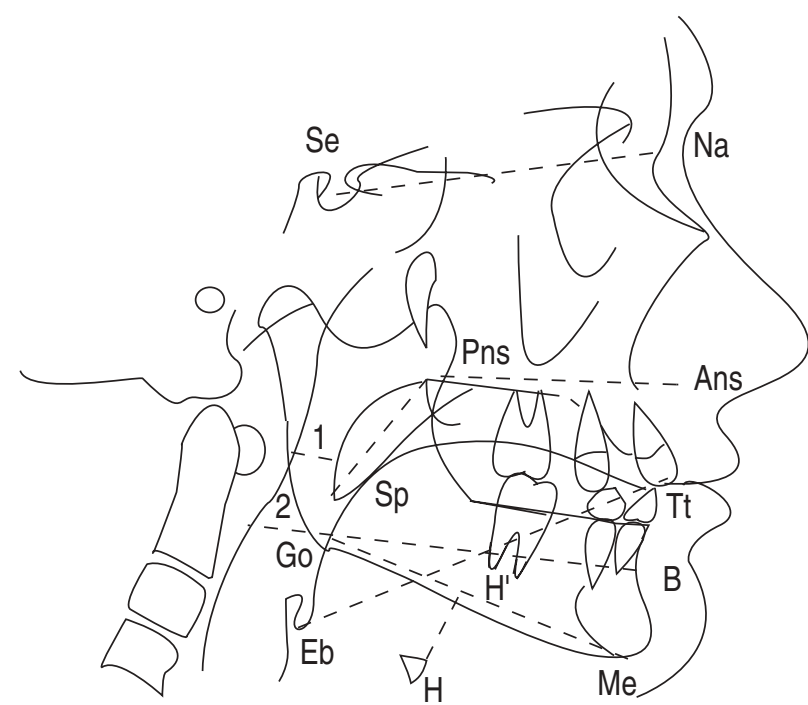

Fig. 2. - Diagrammatic representation of the relevant cephalometric indices measured in table 1 . The spaces labelled 1 and 2 are the posterior superior and inferior airway spaces, respectively. ANS: anterior nasal spine. For further definitions see table 1.

Table 1. - Change in cephalometric measurements over a two year period on nasal continuous positive airway pressure

\begin{tabular}{lcc}
\hline & 13 yrs & 16 yrs \\
\hline PSAS & 2.5 & 4 \\
PIAS & 13 & 16 \\
Go-Me & 70.5 & 74 \\
Eb-Tt (tongue) & 66 & 74 \\
Pns-Sp (soft palate) & 46 & 42 \\
H-H' & 20 & 20.5 \\
H-Me & 37.5 & 38 \\
Na-B & 98 & 100 \\
Se-Na & 68 & 68 \\
Na-Me & 119 & 124 \\
\hline
\end{tabular}

All measurements are in $\mathrm{mm}$ and also refer to figure 2. PSAS: posterior superior airway space; PIAS: posterior inferior airway space; Go-Me: distance from gonion to menton; Eb-Tt: distance from epiglottic base to tongue tip (tongue length); PnsSp: distance from posterior nasal spine to soft palate tip (soft palate length); $\mathrm{H}-\mathrm{H}^{\prime}$ : perpendicular distance from hyoidal process to mandibular plane; $\mathrm{H}-\mathrm{Me}$ : distance from hyoid to menton; $\mathrm{Na}-\mathrm{B}$ : distance from nasion to supramentale (B); Se-Na: distance from centre of Sella to nasion; $\mathrm{Na}-\mathrm{Me}$ : distance from nasion to menton. the continued absence of OSA with an apnoea/hypopnoea index (AHI) $<5 \cdot h^{-1}$. A repeat ECG at this time showed no remaining evidence of right-heart strain. She remains asymptomatic, with no daytime sleepiness, no observed apnoeas and only occasional light snoring.

Lateral cephalometry was performed at the ages of 13 and $16 \mathrm{yrs}$ (at the time of nCPAP discontinuation) and a diagrammatic representation of the measured parameters is given in figure 2 . The two sets of measurements are compared in table 1 and show a significant growth in mandibular length. In addition, there were considerable increases in posterior superior and inferior airway spaces and a reduction in soft palate length.

\section{Discussion}

Reports are limited regarding the impact of nCPAP therapy in older children with OSA and the Robin sequence, who tend to have only mild sleep apnoea [2], although nCPAP has been used successfully in young children [9]. In addition, there is little published information on longitudinal cephalometric data in children with the Robin sequence. However, it is recognized that palatoplasty, carried out to correct speech difficulties, as in the present case, can predispose to OSA [10]. The present report indicates that older children with the Robin sequence and associated OSA may recover from OSA as growth and reconfiguration of the mandible and soft tissues proceed during adolescence. These findings stress the value of managing OSA in older children with Robin sequence nonsurgically, with nCPAP, where this is technically possible, until full bone development has occurred, since surgical approaches designed to lengthen the mandible [11, 12] might disrupt mandibular growth and development if performed at an earlier stage. Indeed, as this case demonstrates, surgery may be rendered unnecessary by spontaneous resolution of the OSA associated with growth. While nCPAP therapy is possible in very young children and infants [9], it is not yet known how this may modify the need for surgery in craniofacial abnormalities and at which age nCPAP therapy is best introduced.

The proportionate increase in mandibular length in this case was significantly greater than the increase in other dimensions related to the upper part of the face and base of the skull occurring during the same period. This finding is typical of growth patterns in the skull at this stage of peripubertal development [13], but as the increase was 
somewhat greater than that of normal females of the same age [14] this finding suggests that some catch-up growth occurred peripubertally in the present case. Unfortunately, lateral cephalometry was not performed at the time of the initial diagnosis and it is possible that the increase in dimensions might have been greater had such initial measurements been available.

Reduced posterior airway space size has been reported to predispose to obstructive sleep apnoea [15], particularly where the hyoid to mandibular plane distance (fig. 2) and soft palate length are increased [16]. The resolution of obstructive sleep apnoea syndrome in this case was probably due to the increased upper airway dimensions related to more anterior positioning of the tongue base, associated with mandibular growth, and to improved mechanical efficiency of the subsequently lengthened genioglossus muscle. Soft palate shortening may also have contributed, although the mechanism of this change is unclear [17]. The exact mechanism and precise anatomical site of obstruction are not certain, however, and pretreatment and follow-up assessments of upper airway structures by video-endoscopy and computed tomography scanning may be necessary to answer this question fully. Oral mandibular advancement devices have also been shown to increase posterior airway spaces, reducing the apnoea/hypopnoea index and snoring in adults with mild obstructive sleep apnoea syndrome [18]. However, little is known of the potential use of these devices in micrognathic children with obstructive sleep apnoea.

\section{References}

1. Robin P. Glossoptosis due to atresia and hypotrophy of the mandible. Am J Dis Child 1934; 48: 541-547.

2. Spier S, Rivin J, Rowe RD, Egan T. Sleep in Pierre Robin syndrome. Chest 1986; 90: 711-715.

3. Tomaski SM, Zalzal GH, Saal HM. Airway obstruction in the Pierre Robin sequence. Laryngoscope 1995; 105: 111114.

4. Cozi F, Pierro A. Glossoptosis-apnea syndrome in infancy. Pediatrics 1985; 75: 836-843.

5. Deegan PC, McNicholas WT. Pathophysiology of obstructive sleep apnoea. Eur Respir J 1995; 8: 1161-1178.
6. Series F, Cote C, Simoneau JA, St. Pierre S, Marc I. Upper airway collapsibility, and contractile and metabolic characteristics of musculus uvulae. FASEB $J$ 1996; 10: 897-904.

7. Deegan PC, McGlone B, McNicholas WT. Treatment of Robin sequence with nasal CPAP. J Laryngol Otol 1995; 109: 328-330.

8. Rechtschaffen A, Kales K. A manual of standardized terminology, techniques and scoring system for sleep stages of human subjects. Washington, DC, National Institutes of Health, 1968, Publication No. 204.

9. Waters KA, Everett FM, Bruderer JW, Sullivan CE. Obstructive sleep apnoea: the use of nasal CPAP in 80 children. Am J Respir Crit Care Med 1995; 152: 780 785.

10. Ysunza A, Garcia-Velasco M, Garcia-Garcia M, Haro R, Valencia M. Obstructive sleep apnea secondary to surgery for velopharyngeal insufficiency. Cleft Palate Cran-iofac $J$ 1993; 30: 387-390.

11. Guilleminault C, Quera-Salva MA, Powell NB, Riley RW. Maxillomandibular surgery for obstructive sleep apnoea. Eur Respir J 1989; 2: 604-612.

12. Frohberg U, Lange RT. Surgical treatment of Robin sequence and sleep apnoea syndrome: case report and review of the literature. J Oral Maxillofac Surg 1993; 51: 1274-1277.

13. Williams PL, Warwick R, Dyson M. Gray's Anatomy. 37th Edn. Edinburgh, Churchill Livingstone, 1989; pp. 367-368.

14. Lewis AB, Roche AF, Wagner B. Growth of the mandible during pubescence. Angle Orthod 1982; 52: 325-342.

15. Tangugsorn V, Skatvedt O, Krogstad O, Lyberg T. Obstructive sleep apnoea: a cephalometric study. Part II. Uvulo-glossopharyngeal morphology. Eur J Orthod 1995; 17: 57-67.

16. Jamieson A, Guilleminauit C, Partinen M, Quera-Salva MA. Obstructive sleep apneic patients have craniomandibular abnormalities. Sleep. 1986; 9: 469-477.

17. Mortimore IL, Kochhar P, Douglas NJ. Effect of chronic continuous positive airway pressure (CPAP) therapy on upper airway size in patients with sleep apnoea/hypopnoea syndrome. Thorax 1996; 51: 190-192.

18. Schmidt-Nowara WW, Meade TE, Hays MB. Treatment of snoring and obstructive sleep apnea with a dental orthosis. Chest 1991; 99: 1378-1385. 